\title{
NOTES
}

\section{Proposal for Designation of F38-Type Caprine Mycoplasmas as Mycoplasma capricolum subsp. capripneumoniae subsp. nov. and Consequent Obligatory Relegation of Strains Currently Classified as $M$. capricolum (Tully, Barile, Edward, Theodore, and Ernø 1974) to an Additional New Subspecies, M. capricolum subsp. capricolum subsp. nov.}

\author{
R. H. LEACH, ${ }^{1 *}$ H. ERNØ ${ }^{2}$ AND K. J. MACOWAN ${ }^{3}$ \\ National Collection of Type Cultures and Respiratory and Systemic Infections Laboratory, Central Public \\ Health Laboratory, London NW9 5HT, England ${ }^{1}$; Institute of Medical Microbiology, University of Aarhus, \\ Aarhus, Denmark'; and Chief Scientist's Group, Science Division, Ministry of Agriculture, Fisheries and
} Food, London SWIP 3JR, England ${ }^{3}$

\begin{abstract}
A subspecies relationship with the existing species Mycoplasma capricolum is appropriate for the F38 group of mycoplasmas, the causative agent of classical contagious caprine pleuropneumonia. We believe that this classification is justified on the basis of the close DNA-DNA relationship recently reported for isolates belonging to the two groups and the other known serological and biological similarities and differences of these organisms. Strain $\mathbf{F 3 8}^{\mathrm{T}}$ ( $\mathbf{T}=$ type strain) and taxonomically indistinguishable strains are therefore proposed as members of a new subspecies of $M$. capricolum, $M$. capricolum subsp. capripneumoniae. Strain F38 (= NCTC 10192) is the type strain of $M$. capricolum subsp. capripneumoniae subsp. nov. As a consequence of this subdivision of the species $M$. capricolum, strains previously classified as $M$. capricolum are now necessarily relegated to subspecies status, as $M$. capricolum subsp. capricolum subsp. nov. Strain California kid (= ATCC $27343=$ NCTC 10154) is the type strain of $M$. capricolum, as well as of $M$. capricolum subsp. capricolum. A taxonomic description of $M$. capricolum subsp. capripneumoniae and a brief amended description of $M$. capricolum subsp. capricolum are presented.
\end{abstract}

Mycoplasma strain $\mathrm{F}^{\mathrm{T}}{ }^{\mathrm{T}}(\mathrm{T}=$ type strain) and other indistinguishable strains that were first isolated in Kenya from the lungs of goats with contagious caprine pleuropneumonia (15) were established as the true causative agent of classical contagious caprine pleuropneumonia $(16,17)$, displacing other mycoplasmal candidates previously associated with this disease $(3,17)$. This etiological relationship has been confirmed in contagious caprine pleuropneumonia outbreaks in other parts of Africa and the Middle East (9).

The appropriate classification for the F38-type mycoplasmas has been contentious. Taxonomic studies established that this group belonged to the genus Mycoplasma and apparently was distinct from previously described members of the genus, except that there was some serological crossreactivity with a few species $(7,8)$. The most important cross-reactions were with some of the five mycoplasmas which, together with the F38 group, had begun to emerge as a potential taxonomic group, the so-called "Mycoplasma mycoides cluster." The members of this cluster exhibited levels of serological or genomic interrelatedness sufficient to cause taxonomic problems (10). This cluster includes the two biotypes of $M$. mycoides subsp. mycoides (the smallcolony and large-colony forms), $M$. mycoides subsp. capri, Mycoplasma capricolum, bovine serogroup 7 (14), and the F38 group. In a taxonomic review of the problems presented

\footnotetext{
* Corresponding author.
}

by this cluster $(4,11)$, Cottew et al. advocated that the levels of DNA-DNA relatedness between members of the six cluster groups should be redetermined, with each group preferably represented by several isolates. These authors gave the highest priority to resolving the relationship between $M$. capricolum and the F38 group, referring particularly to the close serological similarity of these organisms and the high DNA-DNA relatedness value $(80 \%)$ reported for the type strain of $M$. capricolum and strain $F 38^{\mathrm{T}}(2)$.

A resulting study $(1,12,13)$ clarified the genomic relationship between $M$. capricolum and the F38 group by examining five isolates of each taxon (including the type strain of $M$. capricolum [strain California kid] and reference strain F38 ${ }^{\mathrm{T}}$ of the F38 group) in DNA-DNA homology experiments. These comparisons produced intragroup DNA-DNA relatedness values of about 85 to $90 \%$, in contrast to relatedness levels of about $70 \%$ between the two groups. The authors concluded that these results, together with existing knowledge of the cultural, biochemical, and serological properties of $\boldsymbol{M}$. capricolum and F38-like strains, which they reviewed in relevant detail, are strongly indicative of a subspecies relationship between the two taxa (1). In light of these observations, we make the following taxonomic proposals, descriptions, and comments.

Taxonomic proposals and descriptions (i) Allocation of F38 ${ }^{\mathrm{T}}$ and related strains to a subspecies of $M$. capricolum, $M$. capricolum subsp. capripneumoniae subsp. nov. Strain F38 ${ }^{\dot{\mathrm{r}}}$ and other indistinguishable isolates of the causative agent of 
contagious caprine pleuropneumonia (including the isolates examined in the DNA-DNA relatedness studies mentioned above [1]) are closely related antigenically to members of the species $M$. capricolum. This can cause difficulties in the serological identification of wild strains $(1,5,8,11)$. However, the two mycoplasmas have markedly different growth and cultural characteristics; $F 38^{\mathrm{T}}$ is much more fastidious and slow growing. $M$. capricolum and F38-like strains also differ in a major biochemical property; most $M$. capricolum strains can metabolize arginine, whereas F38-like strains cannot $(1,8,20)$. Some similarities, but also distinct differences, are also evident in the electrophoretic protein patterns and isoenzyme profiles of these two groups $(4,18)$. These somewhat countervailing taxonomic features are not inconsistent with the putative subspecies relationship that has been postulated in light of the DNA-DNA relatedness value of $70 \%$ recorded between the two mycoplasma groups (1).

In light of the observations described above and particularly the observations of Bonnet et al. (1), we therefore propose that the F38 group of mycoplasmas should be formally designated a subspecies of $M$. capricolum. We propose the name Mycoplasma capricolum subsp. capripneumoniae for this new taxon.

(ii) Relegation of strains belonging to the existing taxon $M$. capricolum (Tully, Barile, Edward, Theodore, and Ernø, 1974) to subspecies status, as $M$. capricolum subsp. capricolum subsp. nov. The separation of a new subspecies designated $M$. capricolum subsp. capripneumoniae in the species $M$. capricolum, as proposed above, demands reclassification of the strains previously classified as members of the taxon, $M$. capricolum (20). These strains must be allocated to another subspecies of $M$. capricolum, and precedent requires that the subspecies should have the same epithet as the species. We therefore propose that type strain California kid and other strains previously classified as $M$. capricolum should be designated Mycoplasma capricolum subsp. capricolum subsp. nov.

(iii) Taxonomic description of Mycoplasma capricolum subsp. capripneumoniae subsp. nov. Mycoplasma capricolum subsp. capripneumoniae (cap.ri.pneu.mo'ni.ae. L. gen. n. capri, of a goat; L. Gr. gen. n. pneumoniae, of the lung; M. L. gen. n. capripneumoniae, of the lung of a goat). Pleomorphic nonspiral cellular morphology; nonmotile. Lacks a cell wall; bounded only by a single trilaminar cell membrane. Can be filtered through 450-nm-pore-size membrane filters.

Fastidious cultural requirements; needs special media, particularly for primary isolation. Optimal growth occurs at $37^{\circ} \mathrm{C}$; no growth occurs at $22^{\circ} \mathrm{C}$. Produces small colonies on suitable solid media; the colonies have a characteristic fried-egg morphology.

The DNA base composition is $24.4 \mathrm{~mol} \% \mathrm{G}+\mathrm{C}$.

Susceptible to digitonin; requires sterol for growth.

Ferments glucose; does not metabolize arginine or urea.

Shows strong serological cross-reactivity with members of the newly designated taxon $M$. capricolum subsp. capricolum (formerly $M$. capricolum), but otherwise distinguishable from previously described Mycoplasma species.

The main habitat is lungs of goats.

The type strain is strain F38 (= NCTC 10192).

For further details concerning the properties described above, see reference 8 .

(iv) Taxonomic description of Mycoplasma capricolum subsp. capricolum subsp. nov. Mycoplasma capricolum subsp. capricolum (cap. ri. co'lum. L. gen. n. capri, of a goat; L. V. incolere, to dwell; L. part. adj. capricolum, dwelling in a goat). The taxonomic description of $M$. capricolum subsp. capricolum is the same as the description of $M$. capricolum (20), except that members of this subspecies exhibit strong serological cross-reactivity with members of the newly designated taxon $M$. capricolum subsp. capripneumoniae; otherwise, $M$. capricolum subsp. capricolum is serologically distinguishable from previously described $M y$ coplasma species.

The type strain is strain California kid (= ATCC $27343=$ NCTC 10154); this is the type strain of both $M$. capricolum and $M$. capricolum subsp. capricolum.

Comment. The lack of a proper classification and nomenclature for the F38 group of mycoplasmas has been a longstanding anomaly, in view of the importance of this taxon as an animal pathogen. However, a more immediate cause of practical concern has been the serological relationship of the members of this group with the members of $M$. capricolum, particularly with regard to the diagnostic identification of isolates obtained from goats $(4,5,8)$ and also with regard to the legal restrictions attached to specified exotic pathogens in some countries $(1,10,11)$. Despite the known differences in cultural, biochemical, and pathogenic properties between the two groups, their serological similarities, together with their shared caprine habitat, have engendered doubts as to whether field isolates belonging to these groups could confidently be distinguished from each other for diagnostic purposes. Such concerns are not dispelled by our taxonomic proposals, but clear designation of the two groups as separate subspecies of $M$. capricolum does at least provide an official nomenclature for each taxon that reflects the relationship of these organisms while confirming their separate identities. Incidentally, it also makes available formal distinctive names that potentially could be useful officially (for example, in relation to quarantine and importexport controls).

In practice, the two newly designated taxa, $M$. capricolum subsp. capricolum and $M$. capricolum subsp. capripneumoniae, can be distinguished quite effectively from each other in diagnostic laboratories. The principal distinguishing features are cultural and biochemical properties, notably the much more restricted growth of $M$. capricolum subsp. capripneumoniae $\mathrm{F} 38^{\mathrm{T}}$ and the failure of this organism to metabolize arginine. Nevertheless, some more specific method for conveniently identifying either subspecies in laboratories would clearly be desirable. The DNA-DNA differences of these bacteria suggest that genomic probes should be feasible, and some progress in this direction has already been reported $(6,19)$ in the form of a specific probe for each subspecies based upon a genomic fragment of the type strain.

The existence of a proper nomenclature for strains related to strain $\mathrm{F} 38^{\mathrm{T}}$ is potentially useful to clinical veterinary workers. Although the names $M$. capricolum subsp. capricolum and $M$. capricolum subsp. capripneumoniae may seem somewhat cumbersome or confusing when used in full, it is likely that, in practice, the subspecies names will often be used as trivial, colloquial terms to describe the organisms (i.e., simply capricolum and capripneumoniae).

We are most grateful to J. G. Tully for his encouragement and valuable advice in the preparation of the manuscript and to G. S. Cottew for his very helpful criticisms of the manuscript. We appreciate the contribution made by $\mathbf{M}$. M. Salih to our earlier characterization studies of the F38 mycoplasma. 


\section{REFERENCES}

1. Bonnet, F., C. Saillard, J. M. Bové, R. H. Leach, D. L. Rose, G. S. Cottew, and J. G. Tully. 1993. DNA relatedness between field isolates of mycoplasma F38 group, the agent of contagious caprine pleuropneumonia, and strains of Mycoplasma capricolum. Int. J. Syst. Bacteriol. 43:597-602.

2. Christiansen, C., and H. Ernø. 1982. Classification of the F38 group of caprine mycoplasma strains by DNA hybridization. J. Gen. Microbiol. 128:2523-2526.

3. Cottew, G. S. 1979. Caprine-ovine mycoplasmas, p. 103-132. In J. G. Tully and R. F. Whitcomb (ed.), The mycoplasmas, vol. 2. Human and animal mycoplasmas. Academic Press, Inc., New York.

4. Cottew, G. S., A. Breard, A. J. Da Massa, H. Ernø, R. H. Leach, P. C. Lefêvre, A. W. Rodwell, and G. R. Smith. 1987. Taxonomy of the Mycoplasma mycoides cluster. Isr. J. Med. Sci. 23:632635 .

5. DaMassa, A. J., P. S. Wakenell, and D. L. Brooks. 1992 Mycoplasmas of goats and sheep. J. Vet. Diagn. Invest. 4:101113.

6. Dedieu, L., A. Breard, and P. C. Lefêvre. 1992. Development of a species-specific DNA probe for Mycoplasma capricolum. Vet. Microbiol. 32:189-197.

7. Ernø, H., R. H. Leach, and K. J. MacOwan. 1979. Further characterization of mycoplasma strain F38. Trop. Anim. Health Prod. 11:84.

8. Ernø, H., R. H. Leach, M. M. Salih, and K. J. MacOwan. 1983. The F38-like group, a new group of caprine mycoplasmas? Acta Vet. Scand. 24:275-286.

9. Jones, G. E., and A. R. Wood. 1988. Microbiological and serological studies on caprine pneumonias in Oman. Res. Vet. Sci. 44:125-131.

10. International Committee on Systematic Bacteriology Subcommittee on the Taxonomy of Mollicutes. 1985. Minutes of interim meeting, 21 and 26 June 1984, Jerusalem, Israel. Int. J. Syst. Bacteriol. 35:378-381.
11. International Committee on Systematic Bacteriology Subcommittee on the Taxonomy of Mollicutes. 1988. Minutes of interim meeting, 25 and 28 August 1986, Birmingham, Alabama. Int. J. Syst. Bacteriol. 38:226-230.

12. International Committee on Systematic Bacteriology Subcommittee on the Taxonomy of Mollicutes. 1991. Minutes of interim meeting, 1 and 2 June 1988, Baden Baden, Austria. Int. J. Syst. Bacteriol. 41:180-182.

13. International Committee on Systematic Bacteriology Subcommittee on the Taxonomy of Mollicutes. 1991. Minutes of interim meeting, 7 and 8 July 1990, Istanbul, Turkey. Int. J. Syst. Bacteriol. 41:333-336.

14. Leach, R. H. 1973. Further studies on classification of bovine strains of Mycoplasmatales, with proposals for new species, Acholeplasma modicum and Mycoplasma alkalescens. J. Gen. Microbiol. 75:135-153.

15. MacOwan, K. J., and J. E. Minette. 1976. A mycoplasma from acute contagious caprine pneumonia in Kenya. Trop. Anim. Health Prod. 8:91-95.

16. MacOwan, K. J., and J. E. Minette. 1977. The role of mycoplasma strain F38 in contagious caprine pleuropneumonia (CCPP) in Kenya. Vet. Rec. 101:380-381.

17. McMartin, D. A., K. J. MacOwan, and L. L. Swift. 1980. A century of classical contagious caprine pleuropneumonia: from original description to aetiology. Br. Vet. J. 136:507-515.

18. Salih, M. M., H. Ernø, and V. Simonsen. 1983. Electrophoretic analysis of iso-enzymes of Mycoplasma species. Acta Vet. Scand. 24:14-33.

19. Taylor, T. K., K. B. Bashiruddin, and A. R. Gould. 1992. Relationships between members of the Mycoplasma mycoides cluster as shown by DNA probes and sequence analysis. Int. J. Syst. Bacteriol. 42:593-601.

20. Tully, J. G., M. F. Barile, D. G. fi. Edward, T. S. Theodore, and H. Ernø. 1974. Characterization of some caprine mycoplasmas, with proposals for new species, Mycoplasma capricolum and Mycoplasma putrefaciens. J. Gen. Microbiol. 85:102-120. 